\title{
Reflections on Student Cultivation during Trumpet Teaching and Performance
}

\author{
Yan Jiyuan \\ School of Music Shaanxi Normal University, Shaanxi Province, Xi'an, 710100
}

Keywords: Trumpet performance; Music quality; Psychological quality; Music creativity; Teaching method

\begin{abstract}
Compared with other instruments, trumpet has its own characteristics; with its own uniqueness, it can be used to perform different styles of work and win audiences' great favor comprehensively. As a Western music instrument, trumpet has tremendous influence in music circle. It enjoys great popularity in Western music world and has long development history after being introduced to China. However, trumpet did not enjoy a plain sailing during its development in China, and it has suffered from some difficulties. To conquer corresponding barriers in its development, higher demands must be proposed for trumpet teaching in colleges. Firstly, students need to have a clear understanding on relative concepts of trumpet music, such as the application scope of trumpet, its artistic characteristics and the current status of its development so that students can have a flexible application of the music and artistic characteristics of trumpet. Corresponding teaching methods of trumpet need to be innovated and students' integral music qualities need to be strengthened; meanwhile, corresponding methods need to be applied in transforming the current status of students' performance.
\end{abstract}

Among brass-wind instruments, trumpet enjoys great popularity. Its individualized characteristics endow it with resounding, heated and unique artistic styles as well as profound and elegant music effects. However, in actual teaching circumstances, it is very difficult for teachers to give every student satisfactory artistic effects. Therefore, teachers should not follow the prescribed order in teaching or require students to follow teachers' steps frigidly. Innovative teaching must be performed comprehensively, and differential treatment in education and individualized teaching must be united effectively. Teachers must apply appropriate teaching methods in practical teaching so that students can complete corresponding learning tasks. Once teachers conquer the existing bottlenecks in teaching, students are sure to be able to use trumpet flexibly and create resounding and meaningful tones and effects. During this time, teachings can be conducted from the following aspects. For example, they can strengthen students' understanding of trumpet, apply new teaching methods for students and train students' performance in specific methods.

\section{Relative concepts about trumpet}

Trumpet enjoys a large application scope in China at present. It is not only a major instrument in brass band, but also an important instrument in Jazz band. It is well known that the difference between Jazz band and other bands is that Jazz has strong style and tones. Therefore, trumpet can be applied in this strong atmosphere. When it cooperates with saxophone, violin, piano and other instruments, unique styles can be created. In some entertainment circumstance, trumpet can also be seen, such as bars, ballrooms and so on. Since trumpet takes a place in them, it shows that trumpet has strong popularity elements. With increasingly more attention paid to trumpet from bands, trumpet begins to be applied in weddings and other circumstances and furthermore, into the vast common people's life. Eventually, it wins people's acknowledgement and appreciation. As time passes, the propagation scope of trumpet becomes increasingly wider. In conclusion, trumpet enjoys a wide application scope.

With its poignant and strong characteristics, trumpet realizes its high pitch. Therefore, trumpet can perform exciting clarion and euphemistic melodies in performance, and it can perform in the form of solo and concert. Trumpet manifests the theme of instrument and artistic emotions with its 
tones and artistic characteristics so that corresponding artistic fragment is sublimed, and audiences' favors are won. In the well-known Monument to the People's Heroes, trumpet and trombone are used to perform important parts in it. Therefore, the essence in the part are highlighted perfectly, the emotions and vigor are reflected and Monument to the People's Heroes is performed incisively and vividly.

Since trumpet is brought into China from the West, different understandings and applications of trumpet are bound to appear because of different aesthetic standards between China and the West, thereby giving birth to different performance effects between China and the West. In the end, Chinese people begin to have misunderstanding about trumpet and some instrument performers even refuse to choose trumpet. Even real trumpet performers begin to have less interest in trumpet because of teaching problems. This is the development status of trumpet in China, i.e., trumpet does not develop well in China. Once no one appreciates an instrument, it is bound to become an unpopular instrument in music circle.

Among its development status in China, the existence of this series of malpractice leads to some barriers during trumpet's development in China. To conquer these barriers, trumpet educators need to make some improvement in teaching process and create learning methods that are suitable to trumpet performers and make contributions to cultivating numerous trumpet performers in China.

\section{Teaching methods of trumpet performance}

Because of the current teaching status of trumpet, it is known that general instrument performers would rather choose other instrument than choose trumpet, and even trumpet performers do not have too much interest in trumpet. To change this situation, trumpet teachers need to make some improvement and innovation in teaching methods. They should not only strengthen learners' study in theoretical knowledge, but also their skill mastering degree. In the end, trumpet learners will appreciate the lingering charm of it and have corresponding interest. Formalistic knowledge infusion would only stimulate students' boredom of it. Once students' practicableness of trumpet is cultivated, students would create corresponding enthusiasm and interest in the interaction, thereby being devoted to initiative learning. Only when they have enthusiasm in trumpet can their learning enthusiasm and exploration degree be strengthened. All in all, performers' enthusiasm in trumpet is the basis of this course, and this basis determines performers' development degree in this field.

When students have corresponding learning motivation, educators should transform their attention to the cultivation of students' creativity; they should teach students in accordance of their aptitude and pay attention to their thoughts. Only when students' creativity is added in this course of artistic characteristics can the performance effects be more characteristic. During the learning process, when students meet new trouble or have new ideas, educators should not repudiate or criticize them blindly; rather, they should guide students to the formal path or encourage their ideas. In this way, learners' psychological emotions can be protected and their sense of fear and pressure for trumpet will be avoided. As leaders, they must pay attention to learners' psychological state, encourage them more often and reduce their psychological pressure.

Trumpet is a course with artistic characteristics, so educators must pay attention to the cultivation of students' theoretical basis, practical basis and psychological state and so on; meanwhile, they should broaden learners' study vision so that learners' flexible application and innovation of trumpet will become more convenient. Among numerous performers, most people do not have too much achievement in music circle because of their wrong practice method or their ignorance of the cultivation of music quality; on the contrary, the minority of people pay attention to the cultivation of music quality and practice methods, so they stand out in music circle. Therefore, educators must realize this point and suit the remedy to the case. Concerning this situation, during the cultivation of learners' music qualities, not only learners' theoretical basis and practical basis should be strengthened, but also their psychological state should be cared for. For example, learners' tension, stage fright and whether they have different ideas and so on. If teachers can notice this point in teaching, students might have more achievement in trumpet performance. 


\section{Specific methods to cultivate students' performance}

To trumpet performers, the best psychological state during performance is to break through previous performance standard; no matter how badly the performance conditions are, one should try his best to present the best state. To every trumpet performer, various psychological pressure might emerge on the stage. Therefore, performers need to minimize the psychological pressure according to their actual conditions and transform it to strong inner motivation. In addition, trumpet performers need to present relaxed and natural performance posture during performance process; meanwhile, they should focus, control their inner emotions and give full play to the emotions of music. More practice can avoid psychological barriers during accidental scenes or questionable scenes. In the end, students can apply various skills flexibly during performance. This method can help student acquire relative skills by muscle memory; eventually, they can form correct performance behaviors and performance thoughts intangibly, and inner incompatibility can be dealt with.

Trumpet performers not only need to have strong professional performance skills, but also need to strengthen their stamina and strength. To an outstanding trumpet performer, he can maintain his energy well, conquer fatigue when he is very tired and present energetic feelings. To realize this problem, trumpet performer needs to focus on the practice of performance stamina and strength during daily practice; when his physical conditions and mental state are allowed, he can extend his performance time appropriately. Scientific researches show that when pressure reaches $150 \%$ of the scope one can bear, the learning efficiency is the highest, and trumpet performer can strengthen his performance stamina and strength. Pertinent training can solve students' dead zone effectively and decompose the problems that students meet with during performance; furthermore, the difficult problems turned out to be easy, and learners' fear and pressure for trumpet performance can be conquered.

The main purpose of trumpet is to make the music full. Therefore, every trumpet performer needs to conduct large quantities of skill practice so that the sound of trumpet can be fuller during performance; meanwhile, trumpet performance moves can be more standard. To become an outstanding trumpet performer, one must be on top of relative knowledge about trumpet performance and establish his performance awareness during the link of trumpet skill practice. During the practice link, one must pay attention that every trumpet performer needs to realize the coordination between movement system and sense system, construct his own procedure mode by his adaptation to the whole system and give feedback in time. This process can help learners grasp performance skills and techniques and construct correct performance views. Therefore, during the process of strengthening skills, one should focus on improving his ability of work analysis, applying music theory and harmony polyphony.

\section{Conclusions}

During the teaching process of trumpet performance, teachers need to take a lot of time in practical teaching, so they need to have strong responsibility and patience. As for practical teaching, they should cultivate students' learning interest, such as music qualities, knowledge reserves, creative skills and so on. Concerning teaching methods, they should cultivate and train students' qualities continuously. They should work hard to improve the disadvantages in trumpet teaching so that students can be fully devoted to trumpet performance. By innovation and improvement of teaching methods, students can acquire corresponding knowledge and skills, thereby being more than equal to solve relative knowledge problems and psychological problems during trumpet performance. Of course, teachers should create more practice opportunities and more performance platforms for students, simulate real stage performance atmosphere and help students acquire more abundant performance experiences for students, thereby changing the current status in trumpet teaching effectively, training more trumpet performance talents for the country and solving trumpet talent vacancy in music circle of China. 


\section{References}

[1] Wang Bin \& Zhao Chunwu. On Differences between Chinese and Western Music Culture [J], World of Paper, 2011(2):82-83.

[2] Hu Qiuyan, Development and Reform of Chinese Trumpet Performance and Teaching in Recent Two Decades[D], Tianjin Conservatory of Music, 2006.

[3] Wang Hongxing, Reflections on Trumpet Teaching in Major of College Teacher Music Education, Modern Interaction, 2012(9). 